\title{
DOUBLE-PULSE LASER-INDUCED BREAKDOWN SPECTROSCOPY WITH 1030 AND 257.5 nm WAVELENGTH FEMTOSECOND LASER PULSES
}

\author{
O. Balachninaitė, A. Baškevičius, K. Stankevičiūtė, K. Kuršelis, and V. Sirutkaitis \\ Laser Research Centre, Vilnius University, Saulètekio 10, LT-10223 Vilnius, Lithuania \\ E-mail: ona.balachninaite@ff.vu.lt
}

Received 20 October 2009; revised 17 March 2010; accepted 19 March 2010

\begin{abstract}
Double-pulse laser-induced breakdown spectroscopy (DP-LIBS) studies and the comparison with the single-pulse experiments were performed on the steel sample. Two harmonics of the femtosecond Yb:KGW laser at 1030 and $257.5 \mathrm{~nm}$ were combined in the collinear beam geometry to carry out double-pulse LIBS experiments at atmospheric pressure in air. The influence of the delay between the two (NIR pulse was delayed in regard to UV pulse) laser pulses on the LIBS signal intensity was investigated. The inter-pulse delay times were in the range from 0 to $200 \mathrm{ps}$. In the delay range from 0 to $40 \mathrm{ps}$ the LIBS plasma emission intensity increased steadily and in the range from 40 to 200 ps (maximum inter-pulse delay investigated) the plasma lines' emission intensity remained almost constant. LIBS signal intensity increased 3-5 times in comparison with the single pulse case when an optimum inter-pulse delay between the two ablating pulses was used.
\end{abstract}

Keywords: laser-induced breakdown spectroscopy (LIBS), double pulse, laser plasma, laser ablation by femtosecond pulses

PACS: $42.62 . \mathrm{Fi}$, 52.50.Jm, 52.38.Mf

\section{Introduction}

Laser-induced breakdown spectroscopy (LIBS) is a spectroscopic analysis technique that is enjoying a period of active development, with all manner of new applications emerging [1]. It uses a focused, pulsed laser beam which is directed at a target to generate plasma the emission spectrum of which gives information about the elemental composition of the sample. It combines fast analysis with the capability to determine nearly all elements of the periodic table. Although the LIBS method has been in use for more than four decades, prior to 1980 , interest in it centred mainly on the basics of plasma formation. Recently, there has been a renewed interest in the method for a wide range of applications. This is due to the result of significant technological developments in the components (detectors, lasers, spectrometers) used in LIBS instruments as well as emerging needs to perform measurements under conditions not feasible with conventional techniques. One of the main limitations of the conventional LIBS technique is its low sensitivity [2]. In order to enhance emission intensity, to reach lower limits of detection (LOD), and to improve the precision of LIBS, special schemes have been constructed. One possible approach to improve
LIBS sensitivity is the double pulse configuration [35]. In double-pulse LIBS (DP-LIBS) two laser pulses from two different sources (commonly) are used in either collinear or orthogonal propagation geometries. The inter-pulse delay is ranging from picoseconds up to hundred microseconds level. Usually the LIBS measurements are performed by recording the plasma emission signals mostly at some optimum separation delay time between pulses. The optimum value of inter-pulse delay depends on the target material, the energy level of excited states. DP-LIBS was first used by Cremers and co-workers where they demonstrated the increased emission intensities of elements during the analysis of transparent liquids' samples [6]. For the analysis of solids double pulse schemes were first applied by Uebbing and co-workers [7]. The emission signal enhancement in DP-LIBS could be explained through better coupling of laser energy to the target and ablated material, leading to a more efficient production of analytic atoms in excited states [8]. The operating mechanisms are a function of material properties, laser pulse energy and duration, irradiation configuration (collinear or orthogonal), ambient atmosphere, and inter-pulse delay. It is also important to note that during different processes the second pulse interacts with the target and 
plasma plume on different time scales depending on the delay time between pulses. DP-LIBS could be used as a way of analysing the plasma plume through the temporal perturbation by a second laser pulse during various stages of evolution of the process. It could be used for the investigation of the plume propagation, ablation mechanism, and emitting properties of the plasma [9].

In parallel with the most often used nanosecond laser pulses the use of ultra-short laser pulses has been proposed by several authors [10-12]. The ultrashort laser pulse does not interact with the resulting plasma. The shortening of the laser pulse duration yields a shrinking of the heat-affected-zone, which prevents an uncontrollable and often undesirable material removal and modification. The ultrashort femtosecond laser ablation of different metals provides craters with higher precision and control in comparison to the nanosecond laser ablation. The reproducibility of the ablation increases and the redeposition of the material reduces compared to nanosecond regime. The ablation efficiency of ultrashort pulses is very high for any wavelength in the spectral range from UV to IR. Furthermore, femtosecond LIBS shows lower background as a result of absence of laser-plume interaction and this allows one to use the non-gated detection. Nevertheless, the plasma spectral line intensities are lower than line intensities of the plasma induced by nanosecond pulses. One of the suggested approaches to increase the spectral line intensities of plasma produced by femtosecond laser pulses is the use of a double-pulse LIBS technique.

Pronko and coworkers [13] compared single and double femtosecond laser pulse regime. They affirmed that the energy absorption in the femtosecond ablation plasma has a saturable character. The limitation of the saturation effect could be overcome by using time separated pulses. Semerok and coworkers [14] proposed to use two femtosecond laser pulses to enhance the plasma emission signal due to an interaction of the second pulse with the plume produced by ablation with the first pulse. Experiments were carried out on $\mathrm{Al}$ and $\mathrm{Cu}$ targets in ambient air with $800 \mathrm{~nm}$ laser pulses and duration in the range of $50 \mathrm{fs}$ to $10 \mathrm{ps}$. They observed three regimes of laser-target interaction: (i) without plasma shielding, $\Delta \tau<1 \mathrm{ps}$; (ii) an intermediate regime $1 \mathrm{ps}<\Delta \tau<$ $10 \mathrm{ps}$; and (iii) total plasma shielding, $\Delta \tau>10 \mathrm{ps}$. The optimal conditions for plasma re-heating, at which the highest plasma intensity was observed, corresponded to delay times of 100-200 ps. The effect of the second pulse on the crater depth decreases in the 1-10 ps interpulse delay range. With a delay of more than $10 \mathrm{ps,}$ the plasma completely shields the target surface. The plasma formation begins with a 1 ps delay, and for a delay of more than $10 \mathrm{ps}$ the energy of second pulse is used mostly on plasma re-heating. The plasma re-heating by the second pulse mainly leads to an increase of plasma intensity and its lifetime. In similar study, Scuderi and coworkers [9] performed dual pulse ablation of Ti sample in vacuum with $100 \mathrm{fs}$ pulses at $620 \mathrm{~nm}$. They observed signal enhancement by around a factor of 2 for both neutral and ionic emission lines. Two steps were observed: the first one was at inter-pulse delay less than 100 ps and was attributed to interaction of the second pulse with the ejected neutral and ionized atoms and the second one occurred at around $1 \mathrm{~ns}$ and was due to interaction with nanoparticles.

Most researchers use two pulses of the same wavelength for double-pulse LIBS. However, constructing a double pulse scheme with pulses of different wavelength may increase LIBS sensitivity. St-Onge and coworkers [15] proposed to use a UV pulse to increase the ablation and a near IR pulse to enhance the reheating of the plasma. The ultraviolet radiation of lasers is more effective for material ablation because of reduced plasma shielding effect. UV wavelengths offer higher photon energies for bond breaking and ionization than infrared wavelengths. It was shown that nanosecond UV-NIR double pulses can moderately improve LIBS sensitivity compared to NIR-NIR double pulses [15].

In our work we would expect to combine the advantages of ultrafast laser ablation with the expected plasma emission line intensity enhancement of the dual pulse different wavelength scheme. This paper presents double-pulse femtosecond LIBS measurements at atmospheric pressure in air, using ultraviolet $(257.5 \mathrm{~nm})$ and near infrared $(1030 \mathrm{~nm}) 350$ fs laser pulses in a collinear type of configuration with a delay line. The inter-pulse delay times were in the range from 0 to 200 ps. Spectra were collected from sheet steel samples. In most cases enhancement of spectral line intensities has been observed when the pulses were separated by intervals longer than $40 \mathrm{ps}$.

\section{Experimental set-up}

The schematic diagram of the experimental set-up is depicted in Fig. 1. Double-pulse femtosecond LIBS experiments were conducted using one femtosecond laser source PHAROS (Light Conversion Ltd.; PHAROS is built upon conventional chirped pulse amplification technique, employing the seed oscillator, regenerative amplifier, and pulse stretcher/compressor mod- 


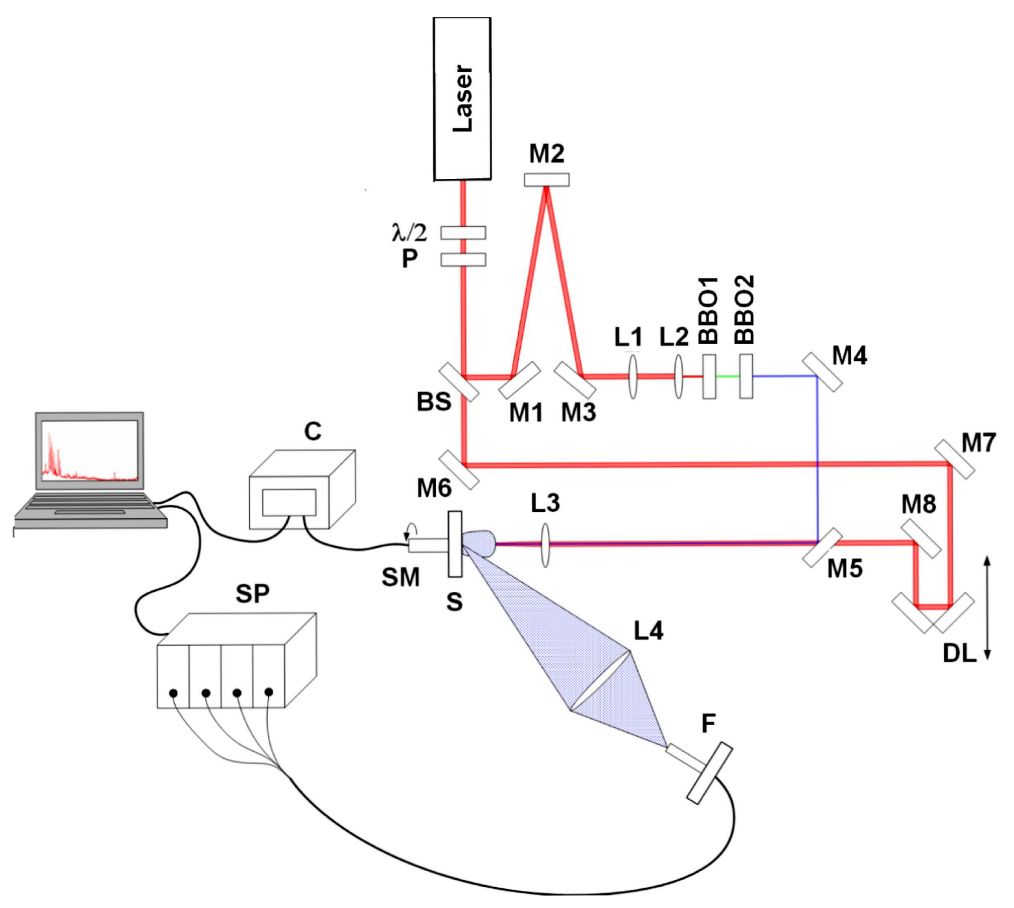

Fig. 1. Experimental set-up. $\lambda / 2$ half-wave plate; $P$ polariser; $B S$ beam splitter; $M 1-M 3, M 6-M 8$ high reflectivity mirrors for fundamental harmonic radiation; $L 1, L 2$ telescope lenses; $B B O 1, B B O 2 \mathrm{BBO}$ crystals (type-I) for second and fourth harmonic generation respectively; $M 4$ high reflectivity mirror for fourth harmonic radiation; $D L$ delay line; $M 5$ dichroic mirror; $L 3$ focusing lens; $S$ sample; $S M$ motorized rotation stage; $C$ controller; $L 4$ collection lens; $F$ fibre optics; $S P$ spectrometer.

ules; regenerative amplifier is based on $\mathrm{Yb}: \mathrm{KGW}$ lasing medium) emitting $350 \mathrm{fs}$ pulses at $1030 \mathrm{~nm}$ with a repetition rate of $50 \mathrm{kHz}$. The fundamental $(1030 \mathrm{~nm})$ and the fourth harmonic $(257.5 \mathrm{~nm})$ radiation was used for the experiment. An attenuator consisted of half-wave plate and polarizer was used to further control the energy content of the primary laser beam. A beam splitter was used to split the beam in two different arms with energy ratio $4: 1$. The main part of the radiation reflected by the beam splitter was directed to the BBO nonlinear crystals (type I; $2 \mathrm{~mm}$ length each) in order to generate the second and after that the fourth harmonics. Before that the diameter of the fundamental beam was reduced approximately 3 times by using the telescope system consisting of plano-convex $100 \mathrm{~mm}$ and plano-concave $33 \mathrm{~mm}$ focal length fused silica lenses. The radiation of the fourth harmonic $(257.5 \mathrm{~nm})$ using the selective mirrors was directed to the target. Another remaining part of the fundamental radiation passed through the beam splitter and with selective mirrors was directed to the delay line. The delay line was equipped with a micrometre resolution motorized translation stage which introduced a controlled time delay, $\Delta \tau$, between fundamental and the fourth harmonic laser pulses within the range of 0-200 ps. The radiation of fundamental and fourth harmonic was coincided at the dichroic mirror. Then two collinear pulses were focused by a $100 \mathrm{~mm}$ focal length fused silica lens down to a spot diameter of about $60 \mu \mathrm{m}$ (at $1030 \mathrm{~nm}$ wavelength). The radiation focused onto the sample which was fixed on a rotation stage controlled by computer. Plasma emission was collected through the convex $75 \mathrm{~mm}$ focal length fused silica lens and focused into an optical fibre. The fibre introduced the light into an imaging four channel spectrometer AvaSpec-USB2-DT (Avantes) equipped with four diffraction gratings, 2400, 2400, 1800, and 1800 lines $/ \mathrm{mm}$, providing spectral resolution of 0.09 , $0.07,0.1$, and $0.08 \mathrm{~nm}$ respectively. The spectra could be collected in 200-664 nm spectral range. But during the experiment plasma spectra were investigated in the $415-500 \mathrm{~nm}$ range as in this range the most intense spectral lines were observed. The spectrometer was equipped with a 2048 pixels CCD detector (Sony ILX554). The registered plasma emission spectra were analysed using "Plasus SpecLine 2.1" software (Avantes).

\section{Results and discussion}

The optimal delay time between the 1030 and $257.5 \mathrm{~nm}$ wavelength laser pulses was found by investigating the influence of the inter-pulse delay $\Delta \tau$ (the fundamental harmonic was delayed in respect of fourth harmonic) on the intensity of the LIBS emission signal 


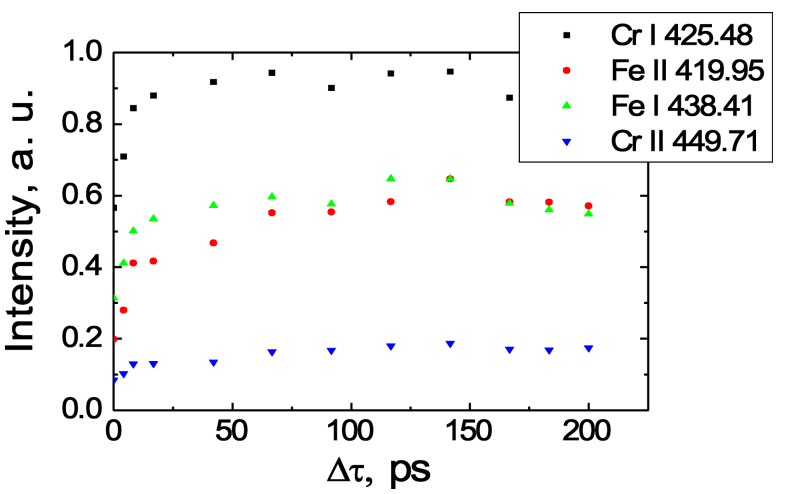

Fig. 2. Influence of the delay time between fundamental and fourth harmonic pulses on plasma emission lines' intensity for several lines of iron and chromium, in double-pulse LIBS measurements on a steel sample.

for various atomic lines. Figure 2 shows how the intensity of different emission lines from chrome and iron (obtained from a steel sample) varies as a function of $\Delta \tau$. From this plot, two main regimes could be defined. First regime is observed in the range of 0 to $40 \mathrm{ps.} \mathrm{In}$ this range the intensity of the emission lines increases steadily compared to the single pulse regime $(\Delta \tau=$ 0 ) and at approximately 40 ps almost constant value is reached. At $\Delta \tau=0$ when the two pulses overlap in time the DP-LIBS measurement with $E 1, E 2$ is equivalent to the single-pulse measurement with pulse energy equal to $E 1+E 2$. In the second regime a plateau is observed from 40 to 200 ps (maximum inter-pulse delay studied in this work). Within this range the maximum emission lines' intensity observed at about $40 \mathrm{ps}$

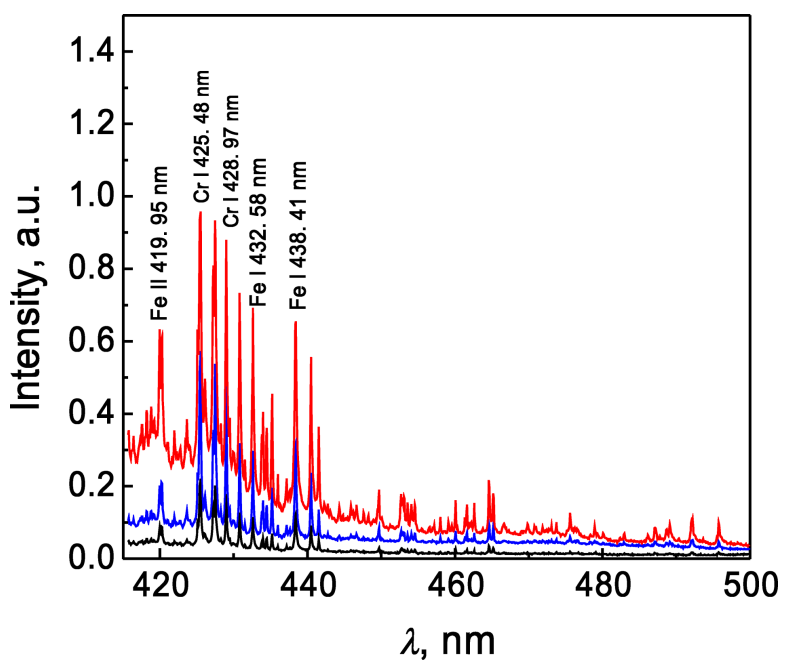

Fig. 3. Comparison of LIBS spectra of steel sample, corresponding to the double pulse at the optimum delay time $\Delta \tau=140 \mathrm{ps}$ (upper curve) (a total energy of $20 \mu \mathrm{J}$ ) and double pulse at $\Delta \tau=0 \mathrm{ps}$ (middle curve) (adequate to the same energy $(20 \mu \mathrm{J})$ single pulse) scheme. The lower curve corresponds to a single fundamental pulse of $10 \mu \mathrm{J}$ energy. remains relatively constant. This behaviour is quite uniform for all the emission lines investigated in this study. In the femtosecond double pulse scheme, all the lines, independent of ionization state, show the same qualitative behaviour with the separation time delay between pulses.

The increase of the intensity of plasma emission lines in the first regime can be attributed to interaction of the second laser pulse with a fast changing sample surface and its immediate environment as noted in the publication of Semerok and co-workers [16]. The processes induced by irradiation of the target with the first laser pulse include absorption (reflectivity) changes (due to electron excitation), electron-lattice energy transfer leading to non-equilibrium phase transitions and melting [17], material ejection, or air plasma formation due to the interaction of electron escaping from the sample with the atmosphere above it [18]. A delay before the plasma plume starts to expand after irradiation moment was estimated to be in range of 1-10 ps [19]. The signal enhancement plateau observed in our experiments at $\Delta \tau>40$ ps could indicate an interaction of the second pulse with the plasma plume.

Double-pulse LIBS spectra of the steel sample used in this study show an enhancement of plasma emission intensity compared to spectra obtained with a single pulse of energy equal to that of the sum of the two pulses in the double-pulse case. Figure 3 shows LIBS spectra obtained from a steel sample both with doubleand single-pulse configurations. The DP-LIBS measurement was performed at an optimum inter-pulse delay time $\Delta \tau=140$ ps with equal energy for the two pulses, $E 1=E 2=E=10 \mu \mathrm{J}$, and the spectrum recorded is about 2-3 times higher in intensity compared to the spectrum obtained with a double pulse at $\Delta \tau=0$ ps (adequate to the same energy $(20 \mu \mathrm{J})$ single pulse). The intensity of DP-LIBS spectrum emission lines is up to 5 times higher compared to the single pulse spectrum corresponding to a pulse energy of $E=$ $10 \mu \mathrm{J}$ (that is actually the spectrum from just the first pulse of the double-pulse experiment).

In order to optimize enhancement factors we are currently investigating the effect of sample position with respect to the focal plane and the influence of the energy balance between the first and second pulse on the intensity of DP-LIBS spectra. 


\section{Conclusions}

Double-pulse laser-induced breakdown spectroscopic measurements by using ultraviolet and near infrared femtosecond pulses in a collinear geometry have been carried out at atmospheric pressure in air. The influence of the delay between the two (NIR pulse was delayed in regard to UV pulse) laser pulses on the LIBS signal intensity was investigated. The inter-pulse delay times were in the range from 0 to $200 \mathrm{ps}$. In the delay range from 0 to $40 \mathrm{ps}$ the LIBS plasma emission intensity increased steadily and in the range from 40 to 200 ps the plasma lines' emission intensity remained almost constant. LIBS signal intensity increased 3-5 times in comparison with the single pulse case when an optimum inter-pulse delay between the two ablating pulses was used. These regimes of laser-sample interaction could be explained by various physical mechanisms including plasma reheating, interaction of the second pulse with a modified sample surface, and formation of air plasma due to interaction of the electrons getting away from the sample with the ambient air.

\section{Acknowledgment}

This work has been carried out with financial support from the Lithuanian State Science and Studies Foundation.

\section{References}

[1] Laser Induced Breakdown Spectroscopy (LIBS): Fundamentals and Applications, eds. A.W. Miziolek, V. Palleschi, and I. Schechter (Cambridge University Press, Cambridge, UK, 2006).

[2] C. Gautier, P. Fichet, D. Menut, J.-L. Lacour, D. L'Hermite, and J. Dubessy, Quantification of the intensity enhancements for the double-pulse laser induced breakdown spectroscopy in the orthogonal beam geometry, Spectrochim. Acta B 60, 265-276 (2005).

[3] P.A. Benedetti, G. Cristoforetti, S. Legnaioli, V. Palleschi, L. Pardini, A. Salvetti, and E. Tognoni, Effect of laser pulse energies in laser induced breakdown spectroscopy in double-pulse configuration, Spectrochim. Acta B 60, 1392-1401 (2004).

[4] F. Colao, V. Lazic, R. Fantoni, and S. Pershin, A comparison of single and double pulse laser-induced breakdown spectroscopy of aluminum samples, Spectrochim. Acta B 57, 1167-1179 (2002).

[5] D.N. Stratis, K.L. Eland, and S. Michael Angel, Effect of pulse delay time on a preablation dual-pulse LIBS plasma, Appl. Spectrosc. 55, 1297-1303 (2001).

[6] D.A. Cremers, L.J. Radziemski, and T.R. Loree, Spectrochemical analysis of liquids using the laser spark, Appl. Spectrosc. 38, 721-729 (1984).

[7] J. Uebbing, J. Brust, W. Sdorra, F. Leis, and K. Niemax, Reheating of a laser-produced plasma by a second pulse laser, Appl. Spectrosc. 45, 1419-1423 (1991).

[8] J. Scaffidi, S.M. Angel, and D.A. Cremers, Emission enhancement mechanisms in dual-pulse LIBS, Anal. Chem. 78(1), 24-32 (2006).

[9] D. Scuderi, O. Albert, D. Moreau, P.P. Pronko, and J. Etchepare, Interaction of a laser-produced plume with a second time delayed femtosecond pulse, Appl. Phys. Lett. 86, 071502-1-3 (2005).

[10] S.M. Angel, D.N. Stratis, K.L. Eland, T. Lai, M.A. Berg, and D.M. Gold, LIBS using dual- and ultrashort laser pulses, Fresen. J. Anal. Chem. 369, 320-327 (2001).

[11] V. Piñon, C. Fotakis, G. Nicolas, and D. Anglos, Double pulse laser-induced breakdown spectroscopy with femtosecond laser pulses, Spectrochim. Acta B 63, 1006-1010 (2008).

[12] O. Samek, A. Kurowski, S. Kittel, S. Kukhlevsky, and R. Hergenröder, Ultra-short laser pulse ablation using shear-force feedback: Femtosecond laser induced breakdown spectroscopy feasibility study, Spectrochim. Acta B 60, 1225-1229 (2005).

[13] P.P. Pronko, Z. Zhang, and P.A. VanRompay, Critical density effects in femtosecond ablation plasma and consequences for high intensity pulsed laser deposition, Appl. Surf. Sci. 208-209, 492-501 (2003).

[14] A. Semerok and C. Dutouquet, Ultrashort double pulse laser ablation of metals, Thin Solid Films 453-454, 501-505 (2004).

[15] L. St-Onge, V. Detalle, and M. Sabsabi, Enhanced laser-induced breakdown spectroscopy using the combination of fourth-harmonic and fundamental Nd:YAG laser pulses, Spectrochim. Acta B 57, 121-135 (2002).

[16] A. Semerok and P. Mauchien, Ultrafast pulse laser ablation for surface elemental analysis, Rev. Laser Eng. 38, 530-535 (2005).

[17] J.P. Colombier, P. Combis, A. Rosenfeld, I.V. Hertel, E. Audouard, and R. Stoian, Optimized energy coupling at ultrafast laser-irradiated metal surfaces by tailoring intensity envelopes: Consequences for material removal from Al samples, Phys. Rev. B 74, 224106 (2006).

[18] S.S. Mao, X. Mao, R. Greif, and R.E. Russo, Initiation of an early-stage plasma during picosecond laser ablation of solids, Appl. Phys. Lett. 77, 2464-2466 (2000).

[19] A. Melninkaitis, T. Balciunas, A. Vanagas, and V. Sirutkaitis, Time-resolved digital holography: a ver- 
satile tool for femtosecond laser-induced damage studies, in: Laser-Induced Damage in Optical Materials: M.J. Soileau, and C.J. Stolz, Proc. SPIE 7504, 750400 2009, eds. G.J. Exarhos, V.E. Gruzdev, D. Ristau, (2009).

\title{
DVIGUBO IMPULSO LAZERIU INDUKUOTOS PLAZMOS SPEKTROSKOPINIAI TYRIMAI ŽADINIMUI NAUDOJANT 1030 IR 257,5 nm BANGOS ILGIO FEMTOSEKUNDINIUS IMPULSUS
}

\author{
O. Balachninaitė, A. Baškevičius, K. Stankevičiūtė, K. Kuršelis, V. Sirutkaitis
}

Vilniaus universitetas, Vilnius, Lietuva

\section{Santrauka}

Pristatomi lazeriu indukuoto optinio pažeidimo medžiagų tyrimai naudojant dvigubus femtosekundinius lazerio impulsus. Ivertinami pagrindiniai dèsningumai ir lyginima su pavieniu impulsu gautais rezultatais. Plazma ant bandinio (plieno plokštelès) paviršiaus buvo indukuojama lygiagrečiai fokusuojant femtosekundinio Yb:KGV lazerio pagrindinès $1030 \mathrm{~nm}$ ir ketvirtosios 257,5 $\mathrm{nm}$ harmonikos spinduliuotę. Buvo stebimas dvigubo impulso lazeriu indukuotos plazmos spektrinių linijų intensyvumo kitimas esant skir- tingiems impulsų tarpams. Jie buvo keičiami nuo 0 iki 200 ps. Esant impulsų tarpams nuo 0 iki 40 ps, stebimas staigus lazeriu indukuotos plazmos emisijos linijų intensyvumo augimas, o nuo 40 iki 200 ps emisijos linijų intensyvumas kinta nežymiai. Nustatyta, kad, esant optimaliam tarpui tarp dviejų impulsų, plazmos emisijos linijų intensyvumas padideja 3-5 kartus, palyginti su lazeriu indukuotos plazmos spektroskopiniais tyrimais, kai plazmai sukurti naudojami pavieniai impulsai. 